\title{
The nitty-gritty on nits
}

I $\mathrm{t}$ almost begs the conclusion that some Canadian school boards are being a trifle nitwitted about nits.

School boards that send children home in disgrace because they have head lice (pediculosis capitis) or nits (lice eggs) in their hair have adopted policies that are based on myths, the Canadian Paediatric Society (CPS) says. No-nit policies, which remove children from school if they have head lice or lice eggs in their hair, are not scientifically justified public health measures, as head lice and nits are not a sign "of poor hygiene or a vector for disease," according to CPS clinical guidelines (www.cps .ca/english/statements/id/id08-06.htm).

Yet, some school boards around the country, such as the Halton District public and catholic school boards in Burlington, Ontario, continue to unapologetically banish children from their premises. And in some instances, such a recent case in Prince Edward Island, school administrators say they are considering a return to no-nit policies because lice are spreading within their corridors.

That's ill-advised policy that achieves nothing except to stigmatize some children, says Dr. Noni MacDonald, professor of pediatrics at Dalhousie University in Halifax, Nova Scotia and coauthor of the CPS's clinical guidelines on head lice.

Rather, schoolchildren found to have head lice or nits in their hair should merely be informed to apply a topical insecticide (often a shampoo) when they get home, according to the CPS's Head lice infestations: A clinical update (www.cps.ca/english/statements /id/id08-06.htm).

Parents have long been horrified of the thought of their child becoming infested with head lice. These creepy crawlers walk across the human scalp, feasting on blood from their host's head. They are ugly. They are itchy. But one thing they are not, says the CPS, is dangerous.

Head lice are not known to spread

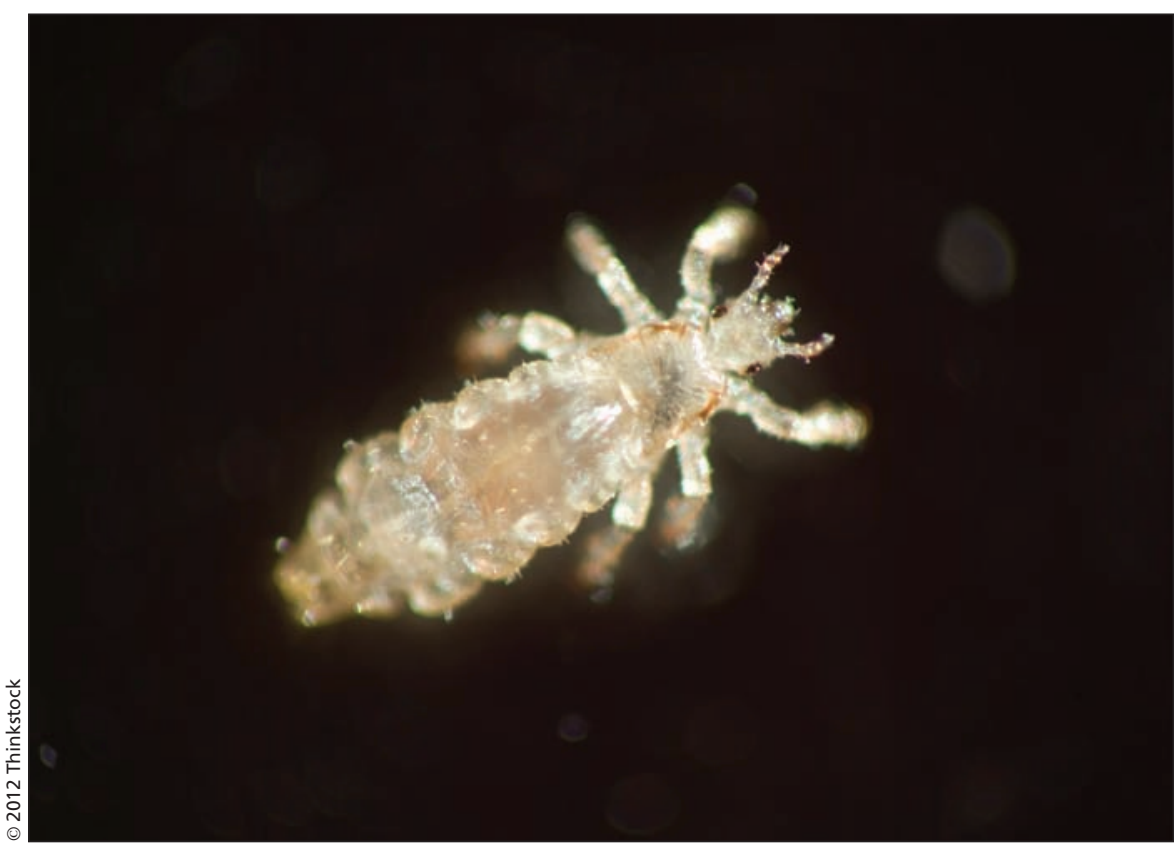

Head lice are not known to spread disease; do not survive long when removed from the scalp; and are only communicable through close head-to-head contact.

disease; do not survive long when removed from the scalp; and are only communicable through close head-tohead contact, CPS states.

Yet, despite the assurances of the absence of health risks from head lice, it remains common for children to be removed from school until their heads are free of the creepy creatures and their ova.

Such practices should be discontinued as the presence of nits does not necessarily mean a person has an active lice infestation (nits must be very close to the scalp to hatch), and nits are glued to the shafts of the hair and thus not transferable to another person, MacDonald and other health professionals and organizations argue.

"You only want kids taken out of school if it's going to improve their health," says MacDonald. "No-nit policies do not improve their health, and that makes it very hard for me to recommend them."

The CPS, along with the American Academy of Pediatrics and others, say children should not be run off the premises but merely informed that they should apply a topical insecticide before returning to school the next day.

Parents might find that baffling, or even distressing. Signs of infestations often send them rushing for shampoos, nit combs or even unproven home concoctions featuring ingredients ranging from vinegar to mayonnaise and gasoline. Head lice are commonly believed to be very persistent, and the cause of endless headaches and stress for both children and parents.

But much of that stress is entirely unnecessary, says MacDonald, who contends that a careful examination of kids in most schools would doubtless reveal that there are children who have head lice "but show no symptoms." The itchiness that is associated with head lice is actually caused by a reaction to the saliva from head lice, she explains, adding that many children are infested for months without anyone knowing.

The entire brouhaha about nits often leaves the medical community in a quandary. It can be as difficult to con- 
vince policy-makers and parents to respond with reason as it is to diagnosis pediculosis. Studies have shown that pediculosis is often misdiagnosed and even trained professionals can be inept at detecting an active lice infestation, often mistakenly identifying dirt, other insects, and clothing fibers as lice or nits, MacDonald notes.

"We're taking children out of school, which is the job of a child, for something that often isn't even an infestation," she adds.

But school boards that have no-nit policies defend the notion of dispatching children with head lice or nits to their family homes.

"In 1997, because of a large number of head lice cases, the superintendents of the Halton District School Board and the Halton Catholic District School Board sat down and wrote the no-nit policy, fully understanding that the Canadian Paediatric Society indicated that head lice are part of the human condition, and therefore should not impact children in schools," says Jacki
Oxley, school and community liaison for the Halton District School Board. "And, of course, I have several physicians remind me of that every year," she adds.

Under the policy, children suspected of having head lice are sent to an approved lice-detection agency (several such organizations exist across the country, including a franchise operation known as The Lice Squad) to determine if he or she has pediculosis capitis. If confirmed, the child is sent home and his classmates are checked to see if they have been infested, as are all of his siblings. Affected children are not allowed to return to school until the screening agency confirms that all of the head lice and nits have been eradicated. The turnaround can take a mere day but no treatments have known to be $100 \%$ effective and in some cases, the nits must be manually removed as shampoos typically do not kill all eggs. The process can be tedious and difficult and it is not uncommon for nits to be missed during a home inspection, so children often miss more days of school.

Parents haven't complained about the policy and the Halton boards have no intention of changing the policy, Oxley says.

MacDonald, though, says the continued defiance of CPS recommendations and parental support for such policy, can generally be attributed to unfounded social hysteria, dating back generations. "I think it's because greatgreat-grandma worried about body lice - and it was bad; people did die from typhus and other diseases from body lice - but there is no risk of anything like that with head lice."

Overcoming that social hysteria will be necessary if more rational nit policies are to be adopted by schools, MacDonald and other public health experts argue, while urging proactive educational approaches in schools and homes to address head lice infestations. Chris Hemond, Ottawa, Ont.

CMAJ 2012. DOI:10.1503/cmaj.109-4173 